\title{
A New Robust Technology of Heart Beat Counting using Transformation by using MATLAB
}

\author{
Suraj Vasantrao Raut \\ Research Scholar, \\ Department of Computer Science \\ \& Engineering \\ IET, Alwar, India
}

\author{
Vineet Mishra \\ Asst. Professor \\ Dr. MPS Group of Institution, Agra
}

\begin{abstract}
This paper presents a new approach to count heart beat from ECG signals. This work is carried out using the Wavelet Transform]. The signals were acquired using an MATLAB SIMULATION of bioelectrical The ECG signals are obtained through the implant of electrodes connected to a channel of the front- end board. The cardiac rhythm is then obtained using an optic dactilar sensor connected to an independent channel of the ECG signal. In order to get a better identification of the acquired the Wavelet family db, sym, coif 4 and bior 1.1 were chosen, primarily because its scaling function is closely related to the shape of the ECG, fitting very well with the applications constraints The processed signals were further analyzed using SIMULATION using MATLAB. The application to count hear beat from the ECG signals was developed by MATLAB 2008Rb and is capable of graphically representing the data before and after it's processed.
\end{abstract}

Keywords

ECG,Db,sym,coif4,bior1.1 and transform.

\section{INTRODUCTION}

Electrocardiography is the process of recording the electrical activity of the heart[4] over a period of time using electrodes placed over the skin. These electrodes detect the tiny electrical changes on the skin that arise from the heart muscle's electrophysiologic pattern of depolarizing and repolarizing during each heartbeat. It is very commonly performed to detect any cardiac problems.

In a conventional 12-lead ECG, ten electrodes are placed on the patient's limbs and on the surface of the chest. The overall magnitude of the heart's electrical potential is then measured from twelve different angles ("leads") and is recorded over a period of time (usually ten seconds). In this way, the overall magnitude and direction of the heart's electrical depolarization is captured at each moment throughout the cardiac cycle.[5] The graph

of voltage versus time produced by this noninvasive medical procedure is an electrocardiogram.

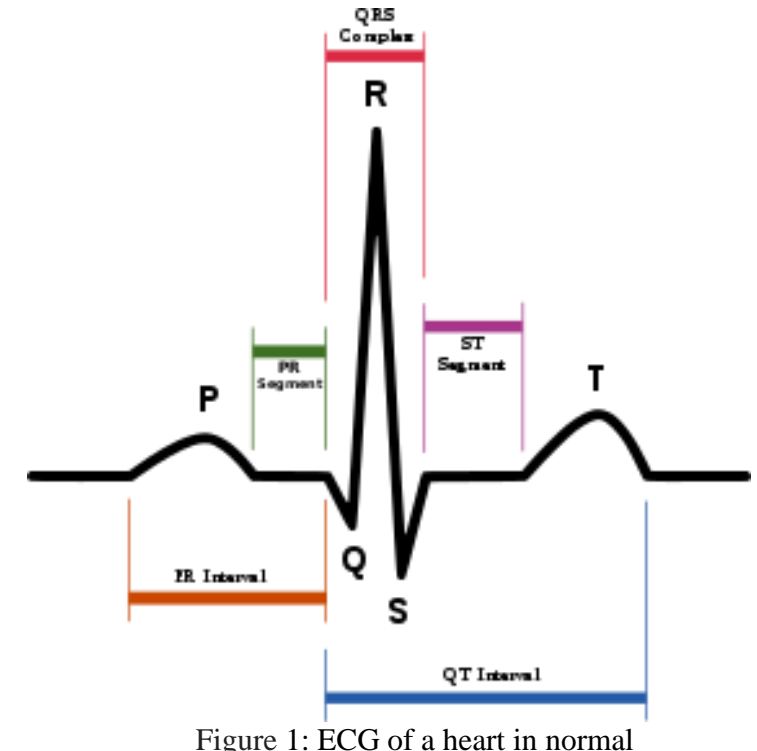

\section{THE DISCRET WAVELET TRANSFORM}

The DWT provides adequatein sequence for the analysis and synthesis of a signal, but is favourably, much more efficient. Discrete Wavelet analysis is computed using the concept of filter banks. B. Compression techniques there are many different forms of data compression [9]. This examination will deliberate on change coding and then more exclusively on Wavelet Transforms. Image data can be represented by coefficients of discrete image transforms. Coefficients that make only small assistance to the information contents can be omitted. However wavelets transform is applied to entire images, rather than subimages, so it produces no blocking artefacts. This is a major advantage of wavelet compression over other transform compression methods. The use of wavelets and thresholding serves to process the original signal, but, to this point, no actual compression of data has occurred". This explains that the wavelet analysis does not actually compress a signal, it simply provides information about the signal which allows the data to be compressed by ISOM which use standard entropy coding techniques, such as Huffman coding. Huffman coding is good to use with a signal processed by wavelet analysis, because it relies on the fact that the data values are small and in particular zero, to compress data.

Wavelets are small time limited waves having zero average value.

Different types of available wavelets are shown in Table. These wavelets are the basis function for wavelet analysis. 
Types of Mother Wavelets Different wavelet families and corresponding mother wavelets are tabulated below. Following wavelets in the last column of the table indicate a wavelet being a part of an infinite family of wavelets.

Table 1 Types of Wavelets

\begin{tabular}{|c|c|c|c|}
\hline $\begin{array}{l}\text { S } \\
\text { r. } \\
\text { N } \\
\text { o }\end{array}$ & $\begin{array}{l}\text { Mothe } \\
r \\
\text { wavele } \\
t \\
\text { family } \\
\text { names }\end{array}$ & $\begin{array}{l}\text { Abbre } \\
\text { viation } \\
\text { s }\end{array}$ & Wavelets \\
\hline 2 & $\begin{array}{l}\text { Daube } \\
\text { chies }\end{array}$ & $\mathrm{Db}$ & $\begin{array}{l}\text { db1 db2 db3 db4 db5 db6 db7 } \\
\text { db8 } \\
\text { db9 db10 db** }\end{array}$ \\
\hline 3 & $\begin{array}{l}\text { Symlet } \\
\text { s }\end{array}$ & Sym & $\begin{array}{l}\text { sym2 sym3 sym4 sym5 sym6 } \\
\text { sym7 sym8 } \\
\text { sym** }\end{array}$ \\
\hline 4 & $\begin{array}{l}\text { Coiflet } \\
\mathrm{s}\end{array}$ & Coif & coif1 coif 2 coif 3 coif4 coif5 \\
\hline 5 & $\begin{array}{l}\text { BiorSp } \\
\text { lines }\end{array}$ & Bior & $\begin{array}{l}\text { bior } 1.1 \text { bior } 1.3 \text { bior } 1.5 \text { bior } 2.2 \\
\text { bior } 2.4 \text { bior } 2.6 \\
\text { bior } 2.8 \text { bior } 3.1 \text { bior } 3.3 \text { bior } 3.5 \\
\text { bior } 3.7 \text { bior } 3.9 \\
\text { bior } 4.4 \text { bior } 5.5 \text { bior } 6.8\end{array}$ \\
\hline
\end{tabular}

\section{LIMITATIONS}

The ECG is one of the most commonly used tests in medicine because it can screen for a large variety of cardiac conditions, the machines are readily available in most medical facilities, the test is simple to perform, is safe, and relatively inexpensive.

That said, an ECG has its limitations:

The ECG reveals the heart rate and rhythm only during the few seconds it takes to record the tracing. If an arrhythmia (heart rhythm irregularity) occurs only intermittently, an ECG might not pick it up, and ambulatory monitoring may be required.

The ECG is often normal or nearly normal with many types of heart disease, such as coronary artery disease.

Sometimes, abnormalities that appear on the ECG turn out to have no medical significance after a thorough evaluation is done.

Risks and Contraindications

ECG is a safe test that does not cause health complications. There are no medical conditions associated with an increased risk or adverse side effects from ECG.

\section{METHODOLOGY/ALGORITHM}

The proposed method is designed for heart beat count with the help of ECG. In below step the method for proposed algorithm is depicted. Heart beat counter System consists of the following step:

Step 1: load ECG

Step 2: Apply Wavelet Transform and select the wavelets family

Step 3: Denoise the signal

Step 4: Apply thresholding on the Signal or compute the approximation coefficient.

Step 4: Apply R detection algorithm

Step 5: Apply Beat Rate Extraction Algorithm

Step 6: Calculate Heart Beat Rate

Step 7: Display Heart Beat Rate
After applying these steps in MATLAB, Design the platform for counting the heart beat with the help of ECG. Run the algorithms and save the result which is shown in below section.

\section{RESULT}

Experiments have been performed to test the proposed algorithm and to measure its accuracy. The system is simulated in MATLAB for EGC sample clinically for the extraction of heart beat. Results are shown in below table along with different supported wavelets family member with percentage error.

Table 1. Heart Rate for Clinical Method and System

Development Algorithm

\begin{tabular}{|l|l|l|l|l|}
\hline Sno & Wavelets & $\begin{array}{l}\text { Clinical } \\
\text { method }\end{array}$ & $\begin{array}{l}\text { System } \\
\text { Method }\end{array}$ & $\begin{array}{l}\text { Percent } \\
\text { Error (\%) }\end{array}$ \\
\hline 1 & Db1 & 77 & 73 & 4.44444444 \\
\hline 2 & Db10 & 77 & 75 & 2.22222222 \\
\hline 3 & Db20 & 77 & 82 & 5.55555556 \\
\hline 6 & Sym2 & 77 & 74 & 3.33333333 \\
\hline 7 & Coif4 & 77 & 76 & 1.11111111 \\
\hline 8 & Bior1.1 & 77 & 73 & 4.44444444 \\
\hline
\end{tabular}

Snapshot of MATLAB are shown in below figure

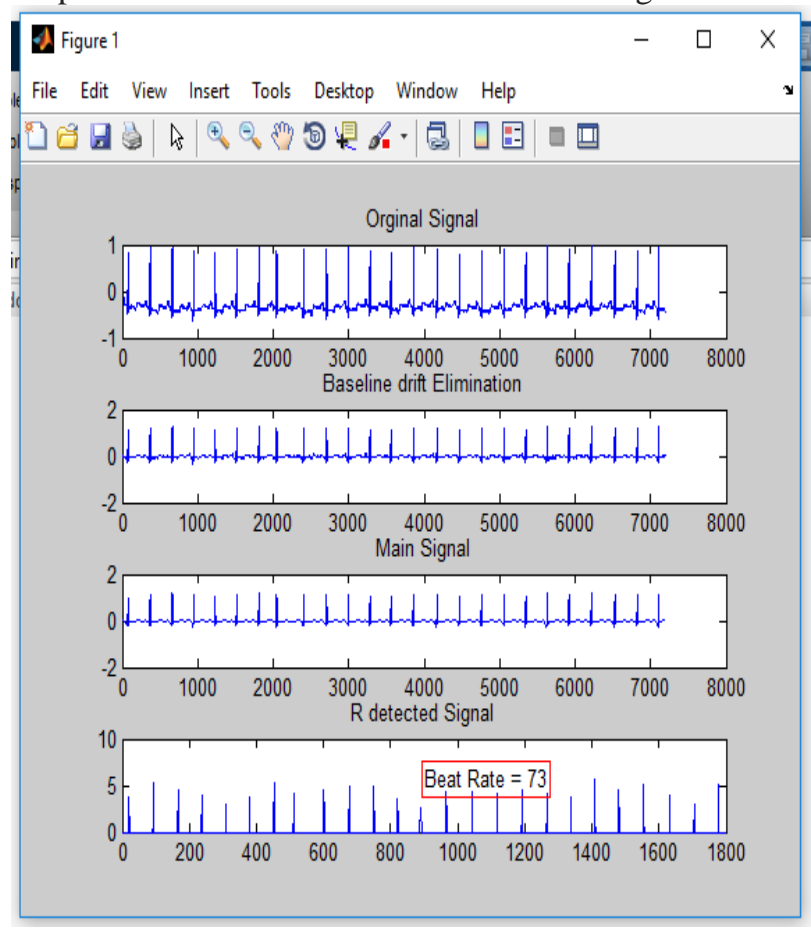

Figure 2: Proposed Algorithms Result Snap Shot

\section{CONCLUSIONS}

We have enforced heart beat counter platform. The system displays the rate of heart. Based on the percentage of error shown in the table, the difference reading is acceptable because the range of percentage errors obtained is in between 1-5\%1. Comparison of heart beat rate with [12]. Its shows the maximum percentage error is $5.7 \%$. Our proposed method showed the maximum percentage error $5.55 \%$ (in table 1). This shows that the estimated values of heart beat rate through system development using algorithm are approximately 
similar to the estimated values through manual estimations using clinically practised method.

\section{REFERENCES}

[1] S. Z. Mahmoodabadi, A. Ahmadian, M.D. Abolhasani, M. Eslami, J.H. Bidgoli, "ECG Feature Extraction Based on Multiresolution Wavelet Transform”, IEEE Engineering in Medicine and Biology 2005. I

[3] Robert J. Huzar, Basic Dysrhythmias, Interpretation and Management (C.V. Mosby Co., 1988.).

[4] Julián Vivas, Luis M. Torres Análisis y Visualización de Señales Electro-Cardiográficas Utilizando la Transformada de Wavelet. Universidad El Bosque, año 2003.

[5] Bert-Uwe Kohler, Carsten Henning, Reinhold Orglmeister, "The Principles of Software QRS Detection", IEEE, Engineering in Medicine and Biology, Jan/Feb 2002.

[6] Donghui Zhang, "Wavelet Approach for ECG Baseline Wander Correction and Noise Reduction", Proceedings of the 2005 IEEE, Engineering in Medicine and Biology 27th Annual Conference.

[7] Gari D. Clifford, Francisco Azuaje and Patrick McSharry, "Advanced Methods and Tools for ECG Data Analysis", Artech House Publisers.
[8] Behzad Mozaffary, Mohammad A. Tinati, "ECG Baseline Wander Elimination using Wavelet Packets", Transactions on engineering, computing and technology, V3, Dec, 2004.

[9] David F. Walnut, An introduction to wavelet analysis, Birkhäuser, c2002 (Pag. 439)

[10] Donoho D L, Johnston I M. Ideal spatial adaptation by wavelet shrinkage. Biometrika.1992 ,81: pp. 425-455.

[11] S. Mallat. A Wavelet Tour of Signal Processing. Academic Press, 2nd edition, 1999. [12] S. Nibhanupudi, R. Youssif, and C. Purdy, "Data-specific Signal Denoising Using Wavelets, with Applications to ECG Data", The 47h IEEE International Midwest Symposium on Circuits and Systems.

[12] Rosmina Jaafar Mohd Aliff Azroy Rozali,"Estimation of Breathing Rate and Heart Rate

from Photoplethysmogram@,978-1-5386-0475-5/17/\$31.00 (C)2017 IEEE.

[13] Tarun Kumar , Karun Verma, 2010a. A theory based on conversion of RGB image to gray image. Int. J. Computer. Appli., 7: 5-12. DOI: 10.5120/1140-1493. 